\title{
Design and Optimization of Micromilling Cutting Tools
}

\author{
Ikhsan Siregar ${ }^{1}$, Juri Bin Saedon ${ }^{2}$ and Mohd Shariman Adenan ${ }^{2}$ \\ ${ }^{1}$ Department of Industrial Engineering, Universitas Sumatera Utara, Almamater Rd., University of Sumatera Utara, Medan \\ ${ }^{2}$ Department of Mechanical Engineering, Faculty of Mechanical Engineering, Universiti Teknologi MARA, Shah Alam, Malaysia
}

\begin{abstract}
With the trend towards miniaturization, micromachining become more and more important in fabricating micro parts. The micromachining process that involved in this study is micro milling. The focus of the study is on the comparison performance between various numbers of flutes (4-flutes, 6-flutes and 8-flutes) with various helix angle $\left(25^{\circ}, 30^{\circ}\right.$ and $\left.35^{\circ}\right)$ in micro end milling tool geometry with the conventional micro end milling, 2-flutes micro end milling. Cemented carbide is the material that been used for this study. The main problem about the two flutes micro end milling is it easily wears in a short time. In this study, finite element analysis of the model using cantilever beam principle theory. The tools will be modelled and simulate using Abaqus/CAE 6.10. The tool performance of the designed tool will be evaluated by using the maximum principal stress, $\sigma \_$max. According to the analysis, weakest geometry is 2-flutes micro end milling and the strongest is 8 -flutes micro end milling. 8-flutes micro end milling can be the option to replace the conventional micro end milling.
\end{abstract}

\section{Introduction}

Micromachining is the most important and basic technology for miniaturized parts and components. Since it became the trend of technological development for few years back, micromachining is expected to play important roles in today's manufacturing technology [1].

Basically, the word micro machining is representing the machining of the dimensions between $1 \mu \mathrm{m}$ to $999 \mu \mathrm{m}$. However, the machining output cannot be achieved directly by a conventional tool, technique and machines [2].

Micromachining is been widely used for mould making that requires small details and finishing [3]. Not only mould making application but micromachining now also been used in bio-medical by machining complex microcavities on aluminum workpiece that can't be obtain by using conventional milling machine [4].

Micromachining is the most basic technology for the production of miniaturized parts and components. Miniaturization becomes the current trend that can benefit the consumer by offering space utilization and portability [5]. Miniaturized technology also may give wide benefit in all type of applications in many fields such as electronic devices, biomedical and others [6].

According to Kalpakjian \&Schmid, milling is the most versatile process that removes the material by a rotating cutter which moves along the work piece Milling process can be done manually and also by mean of computerized machine but for micro milling only computerized machine can be uses to perform the process [7].

Micro milling industry is growing day by day. But it doesn't mean that the available technology is perfect. There are some limitations occurs due to miniaturization of the tool. Some of the tool that available in the market is based on the downsizing of the macro milling tool. The obvious example that been mentioned by Xiang Cheng in his research is the two-flute micro milling. From there, the radial and axial rake angle will be totally change and also the cutting parameters. These small geometry tools will affect the tool life. The tool life will be decreasing synchronized with the size of the tool. As the tool wear and all the processing parameters increase, it is not possible for the tool to break easily [8].

\section{Research method}

Methodology for this research is based on analysis technique. This project required to use relevant reading materials that can be obtained by the previous researches including journals and also books. This project will be focused more on designing the micro end mill and analyse by using Finite Element Analysis (FEA). The software that will be used to perform FEA is Abaqus/CAE 10.1. From here, Maximum principle stress can be obtained and also the region of affect also can be viewed. In this project, the micro end mill tool will be designed in various types of flutes (2- flutes, 4-flutes, 6- flutes and 8 flutes) with various types of helix angle $\left(25^{\circ}, 30^{\circ}\right.$ and also $\left.35^{\circ}\right)$. 
It started with identify problem statement and objectives, scope and significant of project. This process helps to narrow down the focus of the project. Next, is gather information about the title and construct literature review which can be achieved by collecting reading material from journals, papers and also books. This stage also will give more understanding about this project.

After that is modelling the tool geometry and simulate the tool. Firstly, the tool will be modelled and simulated by using the data from previous research. This step is important for continuation with designing various type of tool geometry. The result should be evaluated before proceeding to design various tool geometries.

The process will be done until the suggested tool geometries have been completed to be simulated. The obtained result then will be evaluated by comparing with the transverse rapture stress (TRS). The final process is to construct discussion and conclusion.

The main objective of the static analysis is to determine the deflection of end mills under milling forces. For static deflection analysis of end mills, the tip of tool cutter is assumed to be fixed and the cantilever beam principle method is used.

Two flutes micro end milling is the most popular tool in micro machining. Due to its size and the geometry, the failure of the conventional two flutes end milling tool is very concerning. It seems that the tool life is unpredictable. This is happening because of the downsizing of conventional end milling that can disturb the strength and also the tool life of the micro end milling tool.

The result of this analysis can show the alternative to improve the conventional micro milling end-mills geometry. It also may help to increase the tool life of the tool and may increase the productivity yet may help to lower down the tool replacement cost.

All end mills have a helix angle. In an end mill tool, the direction of helix can be either right handed or left handed. A Right-handed helix means the cutter will remove the chip away from the work piece but this may have a tendency to lift the part.

The shank diameter is the same with the cutter diameter. So, cantilever beam seems to be the suitable for this analysis from there, the maximum principal stress also can be determined. The model will be illustrated as Fig.1.

In this simulation, only the distribution force will be used. The width and depth of the distribution will be represented as the depth of cut and feed per tooth.

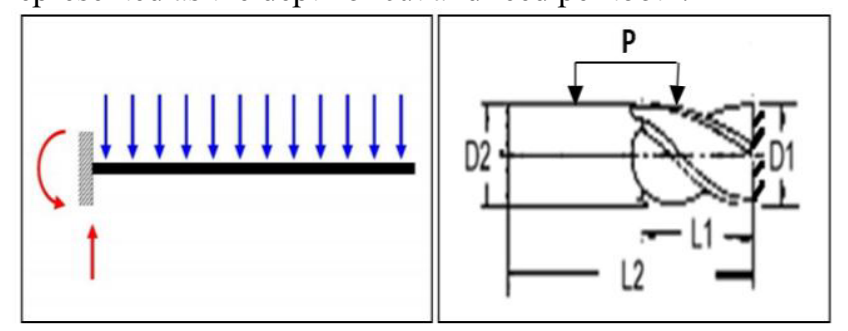

Figure 1. Application of Cantilever Beam Model
There are two types of condition that need to be analysed. First is the maximum principle stress, $\sigma$ max of different number of flute for $30^{\circ}$ helix angle and secondly is the maximum principle stress of different helix angle of each flute.

For tool evaluation, the tool breakage of the designed tool will be evaluated by using the maximum principal stress, $\sigma \_\max$. If the maximum principle stress $\sigma \_\max$ is exceeding the transverse rapture stress (TRS), it will cause chipping to the tool and if the maximum principle stress, $\sigma \_$max is over than the transverse rapture stress (TRS), it will cause breakage. For this material, the transverse rapture stress is $2.73 \mathrm{GPa}$. The result will be also evaluated using the colour contour so that the affected region can be viewed.

According to Juri Saedon (2011) [9], the force for new tool (slot 1) and worn tool (slot 20). For this study the forces that need to be use is Fx because of the direction of the tool movement. This force will be integrated with feed of tooth and depth of cut to obtain pressure where by the pressure will be applied on the cutter only.

Initially the formula of pressure is:

$$
P=\frac{F}{A}
$$

Where,

$$
\begin{aligned}
& \mathrm{P}=\text { Pressure } \\
& \mathrm{F}=\text { Force } \\
& \mathrm{A}=\text { Area }
\end{aligned}
$$

In this case, the area will be substituted with feed of tooth $\left(f_{t}\right)$ and depth of cut $\left(d_{c}\right)$. So, the formula will become:

$$
\begin{gathered}
P=\frac{F_{\text {max }}}{f_{t} \times d_{c}} \\
F_{\text {max }}=12.53 \mathrm{~N}
\end{gathered}
$$

\subsection{Maximum principle stress (Gpa) for different type of flute}

Table 1 shows that the value of Maximum Principle Stress of the micro end mill by using $12.53 \mathrm{~N}$ load and $30^{\circ}$ of helix angle. The highest value is micro end mill two flutes with $3.04 \mathrm{GPa}$ of maximum principle stress. The maximum principle stress for two flutes micro end mill exceed the transverse rapture stress (TRS) which is 2.93 Gpa. From here also we can see that two flutes micro end mill will experience breakage. Most of the tool will experience failure at the tip of the tool (Fig. 2).

Furthermore, the lowest $\sigma_{\max }$ is the eight flutes micro end mill with $0.95 \mathrm{GPa}$. And the value is lower than the TRS. So, eight flutes micro end mill can be used longer duration of time. This also can be done by using six flutes micro end mill as the value only got slightly difference.

Table 1. Result for various numbers of flutes with $30^{\circ}$ helix angle

\begin{tabular}{|c|c|}
\hline Number of flutes & Maximum principle stress (GPa) \\
\hline 2 & 3.04 \\
\hline 4 & 2.10 \\
\hline 6 & 1.43 \\
\hline
\end{tabular}

\section{Result and discussions}



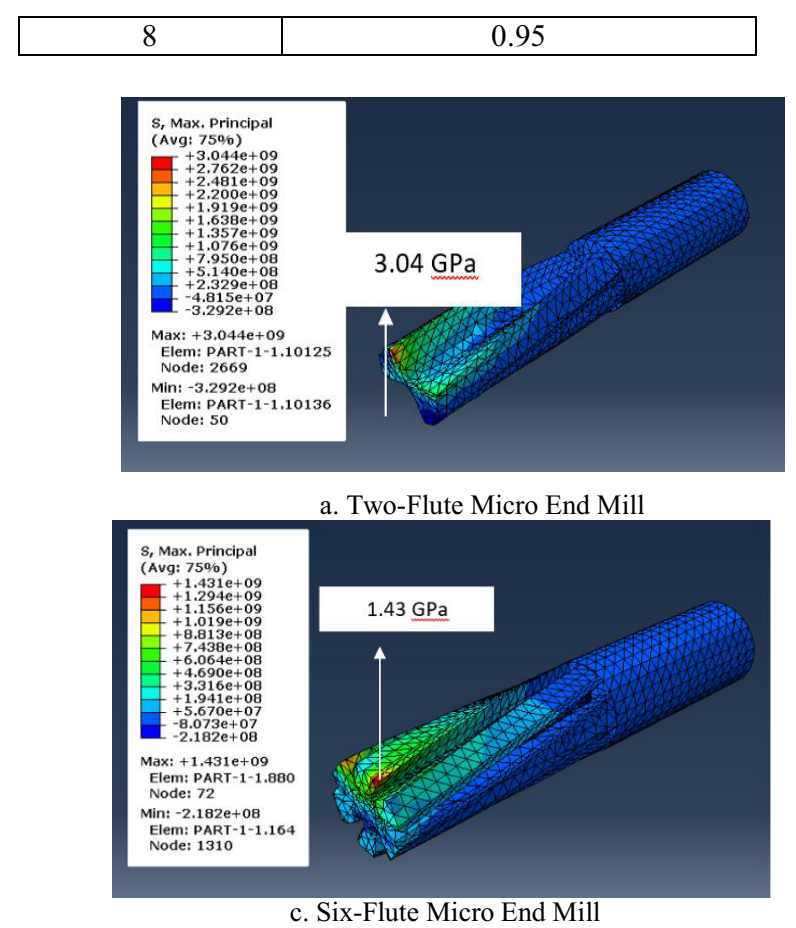

c. Six-Flute Micro End Mill
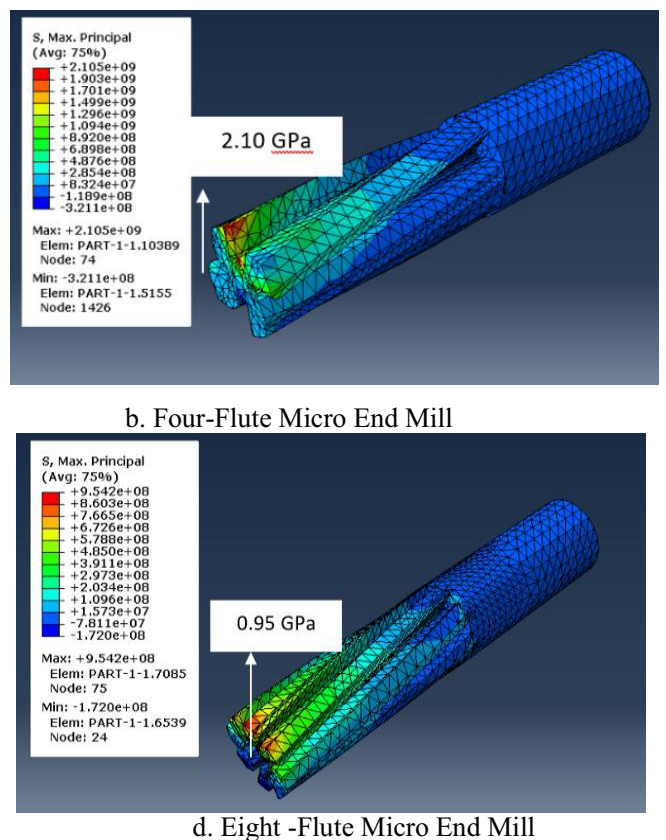

d. Eight -Flute Micro End Mill

Figure 2. Couture of Maximum Principle Stress at The Affected Area $\left(30^{\circ}\right)$

\subsection{Maximum principle stress for different helix angle}

Table 2 presents the value of maximum principle stress for each numbers of flutes when the helix angle is changed to $25^{\circ}, 30^{\circ}$ and $35^{\circ} \mathrm{x}$.

Table 2. Result for Various Helix Angle for Various Numbers of Flutes

\begin{tabular}{|c|c|c|c|}
\hline \multirow{2}{*}{$\begin{array}{c}\text { Number } \\
\text { of flutes }\end{array}$} & \multicolumn{3}{|c|}{ Maximum Principle Stress, $\boldsymbol{\sigma}_{\max }(\mathbf{G P a})$} \\
\hline & $25^{\mathbf{0}}$ & $30^{\mathbf{0}}$ & $35^{\mathbf{0}}$ \\
\hline 2 & 4.19 & 3.04 & 1.09 \\
\hline 4 & 3.01 & 2.92 & 0.92 \\
\hline 6 & 2.35 & 1.00 & 0.59 \\
\hline 8 & 1.26 & 0.95 & 0.41 \\
\hline
\end{tabular}

For micro end tool with $25^{\circ}$ helix angle, two flutes micro end milling and four flutes of micro end mill maximum principle stress $\sigma_{\max }$ beyond TRS that will cause breakage. Similar condition happens with the fourflute micro end mill. Although the value is lower than the two-flute micro end mill but it still will experience breakage. Eight flutes micro end mill obtained the lowest value of $\sigma_{\max }$ and the value of $\sigma_{\max }$ is below than TRS value which is $1.26 \mathrm{GPa}$.

For micro end tool with $25^{\circ}$ helix angle, two flutes micro end milling and four flutes of micro end mill maximum principle stress $\sigma_{\max }$ beyond TRS that will cause breakage. Similar condition happens with the fourflute micro end mill. Although the value is lower than the two-flute micro end mill but it still will experience breakage. Eight flutes micro end mill obtained the lowest value of $\sigma_{\max }$ and the value of $\sigma_{\max }$ is below than TRS value which is $1.26 \mathrm{GPa}$.

Based on the simulation that being done (helix angle $35^{\circ}$ ) it shows that majority of the micro end tool has achieved the value of $\sigma_{\text {max }}$ below TRS. The result for $35^{\circ}$ helix angle is more stable than the rest. Where the $\sigma_{\max }$ is much lower than the $25^{\circ}$ and $30^{\circ}$. The contour of affected area also can be viewed at figure 3 and 4 .

\subsection{Proposed tool geometry}

From the simulation that been done, clearly shows that the best tool is eight Flutes with $35^{\circ}$ of helix angle. The Maximum Plane Stress that been achieved is the lowest of all designed tool which is $0.41 \mathrm{GPa}$. As the value of $\sigma_{\max }$, is the lowest so it's mean that the tool has a longer tool life.

\subsection{Analysis}

There are slightly differences between the researcher's results with the results that been obtained using ABAQUS/CAE 10.1. Firstly, the reasons for these differences are the diameter of the cutter. The diameter of the tools is $0.25 \mathrm{~mm}$ and also the helix angle may be difference as the helix angle is not mentioned. 


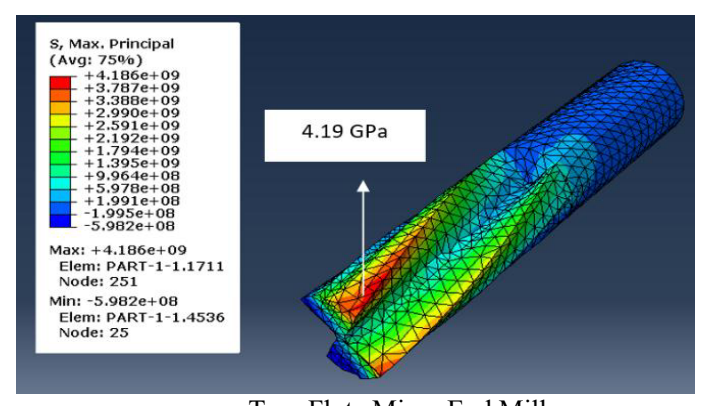

a. Two-Flute Micro End Mill

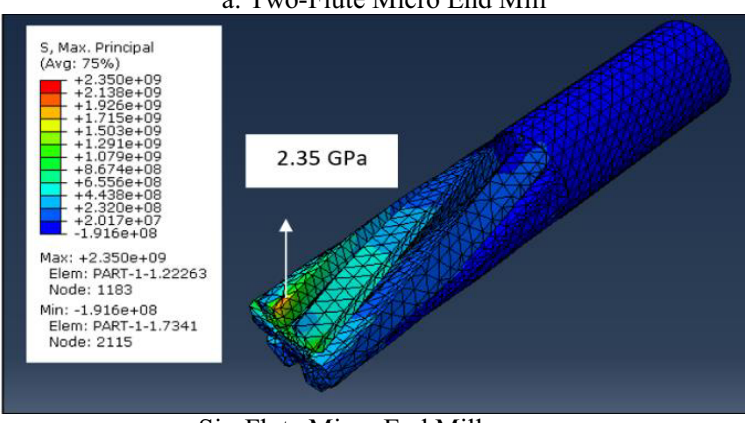

c. Six-Flute Micro End Mill

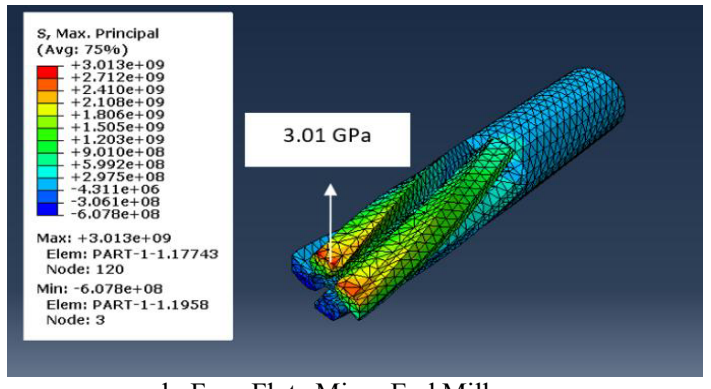

b. Four-Flute Micro End Mill

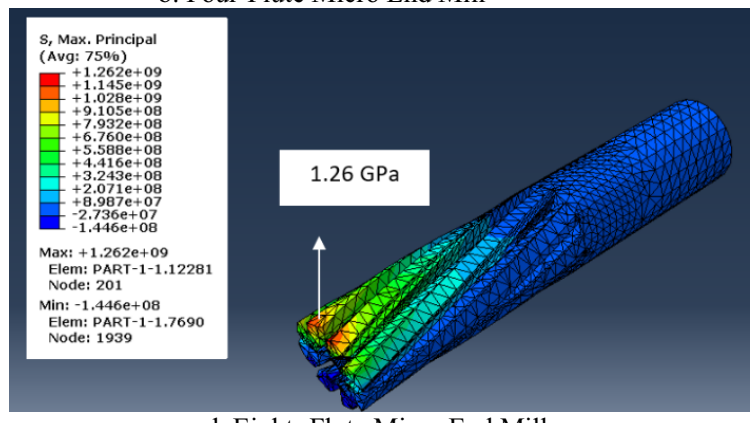

d. Eight -Flute Micro End Mill

Figure 3. Couture of Maximum Principle Stress at the Affected Area $\left(25^{\circ}\right)$

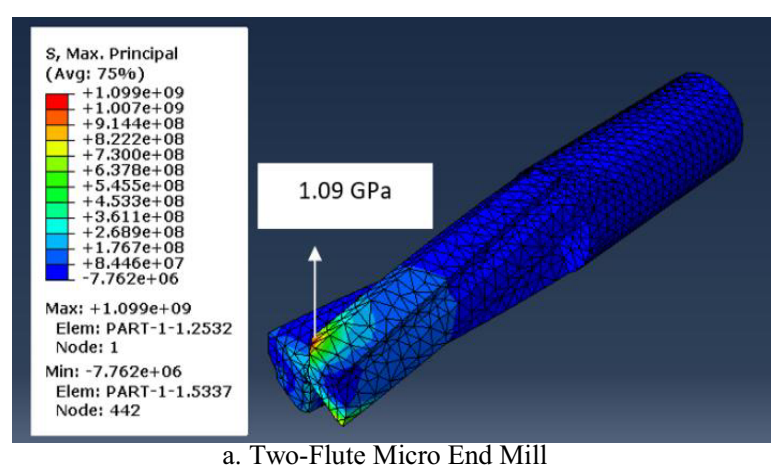

a. Two-Flute Micro End Mill

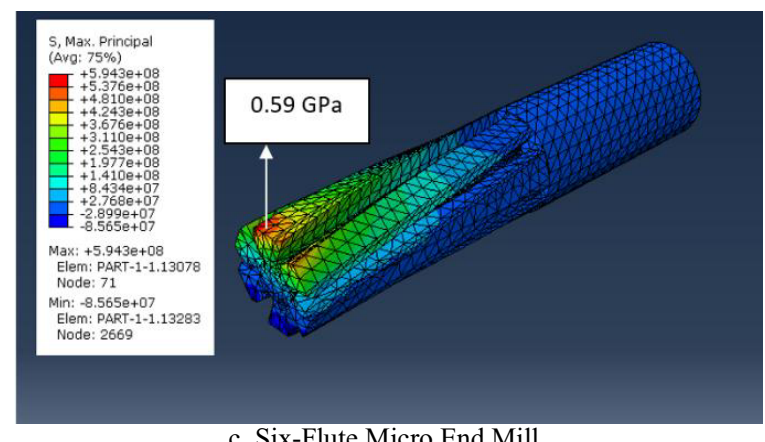

c. Six-Flute Micro End Mill

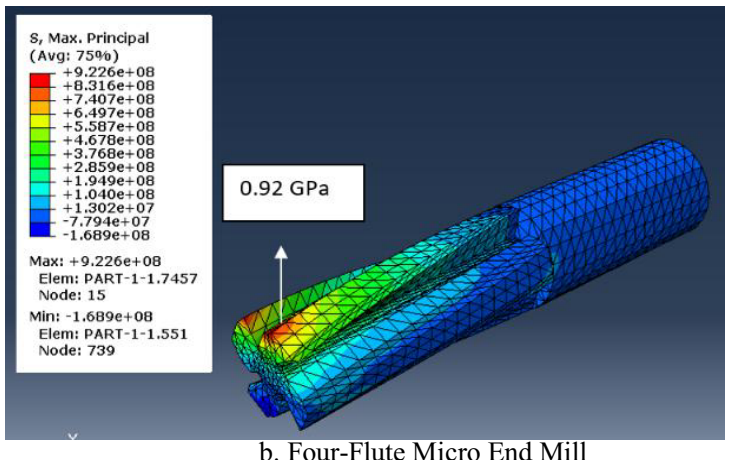

b. Four-Flute Micro End Mill

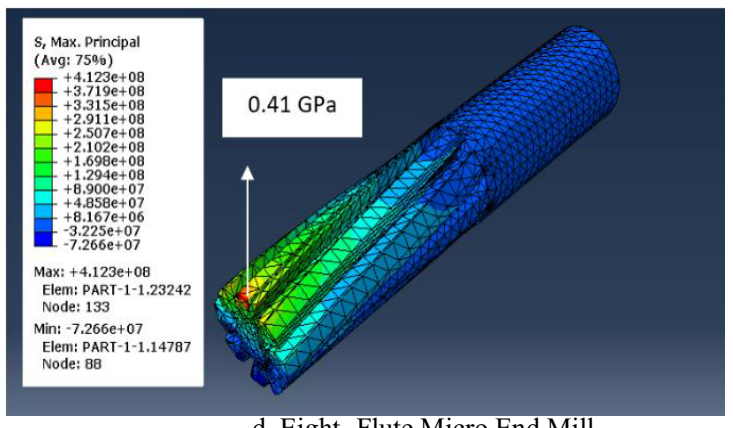

d. Eight -Flute Micro End Mill

Fig. 4. Couture of Maximum Principle Stress at the Affected Area $\left(35^{\circ}\right)$ 


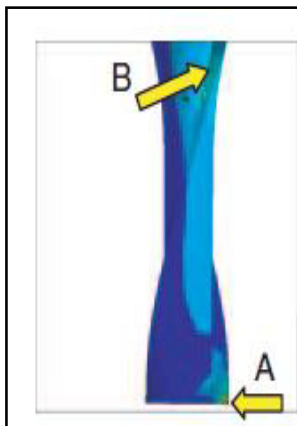

(a)

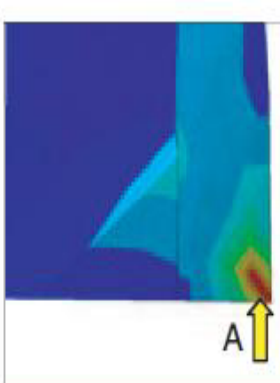

(b) a. Result From F.Z Fang et al [5]

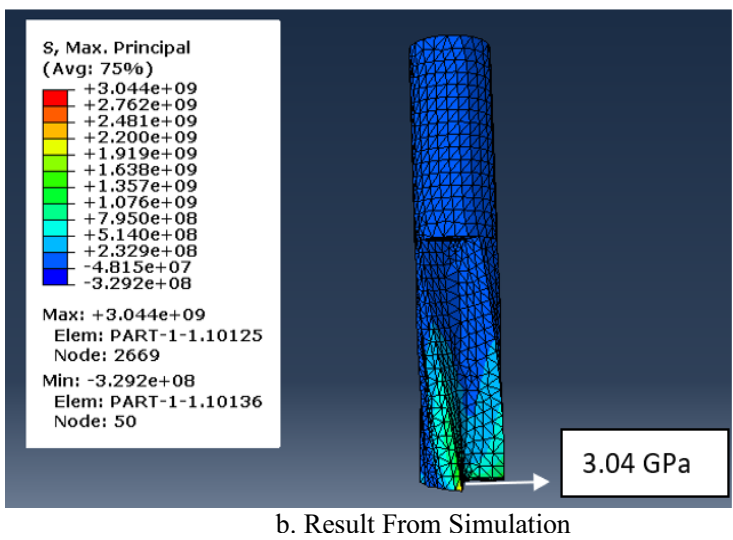

b. Result From Simulation

Figure 5. Differences Result between Previous Researches and Simulation Result

Next is the tool geometry. F.Z Fang et al analyse various shapes of tool such as various types of end-mills in micromachining (Fig.6) (a) Two-flute end-mills, (b) $\Delta$-type end-mills with a straight body, (c) D-type endmills with a straight body, (d) $\Delta$-type end-mills with a tapered body and (e) D-type end-mills with a tapered body. The force that been applied to the cutter is different with the applied force in the simulation. For this simulation, the force that been applied is $12.53 \mathrm{KN}$ but the force that FZ Fang et al is $0.01 \mathrm{~N}$ [5].

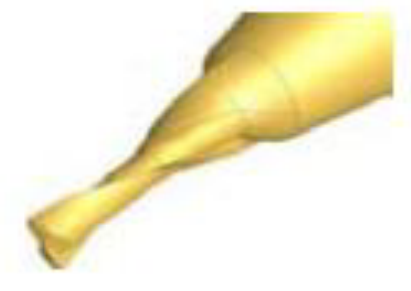

(a)

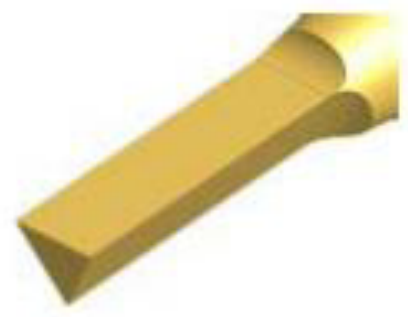

(b)

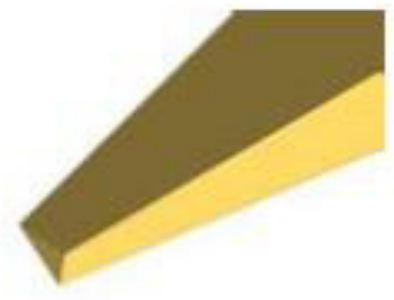

(d)

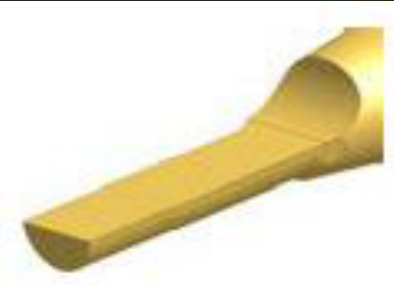

(c)

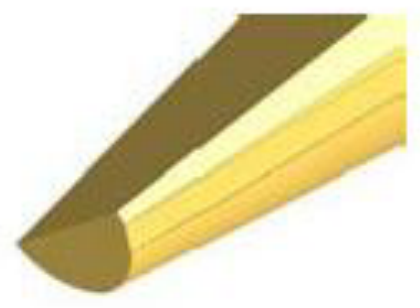

(e)
Figure 6. Various types of end-mills in micromachining

\section{Conclusion}

In conclusion, this project has been successfully accomplished by fulfil all of the objectives using Finite Element Analysis software that is ABAQUS/CAE 6.10. From the result achieved, it clearly shows that lower helix angle will reduce the tool life of the micro end mill. It also proves that the numbers of flutes play a big role in the tool life. From the simulation also we can see that, the region that affected is at the tip of the tool Here, eight flutes with $35^{\circ}$ helix angle micro end mill has the most stability with the lowest value of maximum principle stress, $\sigma_{\max }$. The lowest stability so far is the two-flute micro end mill which obtained the highest maximum principle stress, $\sigma_{\max }$ in any angle.

\section{References}

1. M. Rahman, , H.S. Lim, K.S. Neo, A. Senthil Kumar, Y.S. Wong, X.P. Li. (2007), Tool-based nano finishing and micromachining, [1] Journal of Materials Processing Technology, Vol. 185, pp. Pages 2-16.

2. T. Masuzawa and H.K.Tonshoff (1997), ThreeDimensional Micromachining by Machine Tools, [1] Presented at the Scientific Technical Committee Paper Discussion Sessions.

3. G. Bissacco, H.N. Hansen, L. De Chiffre. 2-3, 30 August 2005, Micromilling of hardened tool steel for mould making applications, Journal of Materials Processing Technology, Vol. Volume 167, pp. 201207.

4. J. Gomar, A. Amaro, E. Vázquez, J. Ciurana, and C. Rodríguez. 2011, Micro-machining of 3D geometries for medical applications, The 4th Manufacturing 
Engineering Society International Conference (Mesic) (2011), pp. 449-456.

5. F Z Fang, H Wu, X D Liu, Y C Liu and S T Ng. 2003 , Tool geometry study in micromachining. Micromech. Microeng. 13 , pp. $726-731$.

6. Ziyang Cao, Hua Li 2010, Investigation of MicroMilling Force Based on Miniature Machine Tool, A pplied Mechanics and Materials, Vol. 29-35, pp $1074-$ 1078.
7. Serope Kalpakjian, Steven Schmid, 2006, Manufacturing Engineering and Technology, Pearson Prentice Hall 2006.

8. Xiang Cheng, Zhigang Wang, Kazuo Nakamoto \&Kazuo Yamazaki, A study on the micro tooling for micro/nano milling, Int J Adv Manuf Technol (2011) 53:523-533.

9. Juri Bin Saedon, October 2011, Micromilling Of Hardened (62 Hrc) Aisi D2 Cold Work Tool Steel 